\title{
Disinformation Reinforces Female Political Inequality and Social Misogyny
}

\author{
Xiangyu Ouyang ${ }^{1, *}$, Yiyao Zhu ${ }^{2}$, Shubing Luo $^{3}$, Chanel Huang ${ }^{4}$ \\ ${ }^{1}$ International College of Beijing, China Agriculture University, Beijing 100085, China \\ ${ }^{2}$ The Pennington School, Pennington NJ 08534, America \\ ${ }^{3}$ Capital Normal University High School, Beijing 100048, China \\ ${ }^{4}$ Shanghai High School, Shanghai 200231, China \\ *Corresponding author. Email: 1214219551@qq.com
}

\begin{abstract}
Disinformation has been a major issue affecting American society for a long time. The female community, as an important part of society, is suffering from the oppression caused by disinformation. This oppression is manifested in two ways, first in the political arena and second in the misogyny of society. Not only that, but with the development of technology, such as the booming development of social media and the emergence of new intelligent AI, it has strengthened the prejudice of the public against the female group caused by disinformation. This article will analyze the impact of disinformation on women's political and social misogyny and will clarify concerns about the future of technology-enhanced female oppression.
\end{abstract}

Keywords: disinformation, political, misogyny, artificial intelligence.

\section{INTRODUCTION}

As various social platforms are diffusing information, they are also creating disinformation to people. Disinformation is defined as "the deliberate creation and sharing of false manipulated information that is intended to deceive and mislead audiences, either for the purposes of causing harm, or for political, personal or financial gain" (Buchanan) [1].

The development of technologies, such as AI and algorithms, have further contributed to the quick spread of fake news, and the reason towards reporting disinformation to the public is complicated: for more attractions and click rates, caught at the shadow, or to incite public emotion.

For instance, in terms of inciting emotions, our instinct assists the spread of disinformation. Research found that People prioritize emotions over facts and evidence, and many consider themselves to be incapable of distinguishing fake contents from truth, which contribute to the exponential spread of false information (Herrero-Diz, Pérez-Escolar \& Plaza Sánchez) [2].

As a result, disinformation, with the help of people's limited ability in identifying the fake news, is creating threats and crises to the whole society. One of the most serious threats intensified by disinformation nowadays is gender inequality. Gender inequality is a long-term problem starting from early times to today. With the spread of disinformation, the negative stereotype toward women gets strengthened, and they become the target of deliberately intended false, inflammatory, and biased information dissemination.

A case in point is Hillary Clinton. During the 2016 U.S. election between Hillary Clinton and Donald Trump, she was negatively influenced by two famous disinformation on social media-- Pizzagate and Hillary Health Scare. Many Hillary-haters and impressionable people truly believed in this seemingly absurd disinformation. Although both disinformation circulating online were eventually proven false and the people involved were brought to justice, the false, negative information about Hillary continued to influence people's opinion of Hillary Clinton and the subsequent presidential election.

As seen in the case of Hillary, disinformation is damaging women's image in public and can easily affect the target audience with its biased message that's aligned with those users' attitude and belief. 
If Hillary is discriminated against due to the spread of disinformation, will all women in society face even more problematic challenges?

Such assumptions aren't unfounded as seen in the fake videos created by Deepfake software-- formats of fake video that replace someone's appearance by using artificial intelligence. Women become the main victims of media disinformation and are manipulated by distortions of their image and words. Misogyny keeps the fake news industry afloat through the accessibility of social media and is detrimental to women as victims of pornography for instance (Herrero-Diz, Pérez-Escolar, Plaza Sánchez) [2].

Therefore, in this article, we will focus on the two main ways in which social media platforms contribute to the discrimination against women in Americaamplifying misogyny and creating male-dominated politics_and what can all social platforms do to monitor the spread of disinformation.

\section{ANALYSIS}

\subsection{Women in politics}

First, disinformation about women in politics, deliberately created by artificial intelligence, has proliferated online and has oppressed women in the political sphere by tarnishing their reputations and thereby reducing the impact of their political advocacy. These disinformation includes deliberately fabricated scandals and pornography against women politicians. There is a bias in social media itself between male and female candidates, such as the belief that women are not as politically tough as men and that women cannot be leaders like men (Setzler) [3]. However, this bias has put the female population at a disadvantage in politics. Yet this bias is not the only barrier to women's voices in politics (Byerly) [4]. The negative messages conveyed to the public by disinformation against female politicians exacerbate the bias of the masses against female politicians. (Carli \& Eagly) [5]. One of the best illustrations of this view is the 2016 U.S. election. In the 2016 U.S. presidential campaign between Hillary Clinton and Donald Trump, there was two very famous disinformation about Hillary on social media ---Pizzagate and Hillary Health Scare. Pizzagate tells the story of Hillary and her campaign manager, and Hillary's husband and former President Bill Clinton had been running a child abuse and sex trafficking ring out of a Washington, D.C. pizza parlor for years (Kang) [6]. This claim may seem absurd, but there are still plenty of Hillary-haters who believe it and call her and her associates names, and the drama ended when a North Carolina man armed with an automatic rifle shot his way into a pizzeria where no abused children existed (The Guardian) [7]. to the date Welch walked into the pizza restaurant, \#Pizzagate and related hashtags were shared about 1.4 million times by more than 250,000 accounts. (Mihailidis \& Viotty) [8]. While Hillary Health Scare this disinformation fiasco came during the first presidential debate when Trump questioned whether Hillary's health could last through the presidency, which set the stage for a large number of people to later believe that Hillary's health was indeed in question. So many pictures of Hillary's grandmother and her sickly state were then circulated on the Internet that even a cough due to seasonal allergies was later considered to be her end of life. (Stabile, Grant, Purohit \& Harris) [9]. Although both of these disinformation circulating online were eventually proven false and the people involved were brought to justice, the false, negative information about Hillary continued to influence people's opinion of Hillary Clinton and the subsequent presidential election. During the same period, her opponent Donald Trump was also deeply involved in the Pussygate scandal (Persaud) [10]. But this comparison to Hillary as a female candidate, Pussygate received far less attention than the former. According to survey statistics, between August 2016 and December 2016, people searched for keywords about Hillary's disinformation on Twitter nine times more often than Trump's, while keywords appeared six times more often in News articles (Stabile, Grant, Purohit \& Harris) [9]. This shows that people pay more attention to negative information about female candidates than male candidates in the same platform of disinformation. In the process, people's own biases against female politicians continue to be amplified, for example, Hillary Health Scare reinforces the stereotypical labels of "thin" and "weak" in women which has led to the idea that women are not as good politicians as men. People's preconceptions about women combined with their preference for negative messages about female politicians on social media make it more difficult for women to gain a voice in the political arena. As a result, disinformation in the U.S. exerts oppression on women in politics, and this oppression exacerbates gender inequality in the country.

However, the impact of disinformation on the political status of men and women will be more serious in the future. Because with the development of technology, the creation and dissemination of disinformation is becoming easier and faster. In the past, the creation of a disinformation or news story required artificially written plots and scripts, and sometimes the whole script was staged in reality to make the whole story sound vivid and add credibility, and most disinformation was operated by governments for political purposes. A typical example is the Soviet "Operation Neptune" (Asiedu) [11], The Soviets invested a lot of manpower and resources to create a fake news story to plant evidence against East German government officials. It was even thought that twenty years of rust had been added to the evidence to make it appear real. From this story, we can see how much effort was required to create 
convincing disinformation in those days. Not only do you need a complete script with no omissions, but you also need well-made props (the Soviets made the box look real and corroded for 20 years on purpose), and finally, you need journalists from all over the world to come and photograph the evidence for propaganda back home. With the massive popularity of the Internet, this process of faking has become much easier. As in the case of Pizzagate we mentioned above, the disinformation did not need to imprison children in a pizza parlor but had a huge impact on the entire presidential election with graphic descriptions and the influence of the dark side of social media (Talwar, Dhir, Kaur, Zafar \& Alrasheed) [12]. Imagine, then, if all such false stories against female politicians' attention-grabbing stories were generated automatically and accompanied by relevant images or videos to enhance their credibility, eventually these disinformation could be targeted and pushed to the target group. In the future, when women candidates participate in the U.S. presidential election and other elections, they will be subject to more serious cyber malicious attacks, and their image will be more seriously damaged in the public.

Negative speculation about the future of women's politics is not unfounded; increasingly sophisticated AI technology will drive disinformation. This means that AI will be used as a tool to allow those with a bias against women to produce more, more specific, and more indistinguishable disinformation about women candidates. In September 2020, an intelligent AI bot named GPT-3 wrote an article about convincing humans that robots are peaceful (The Guardian) [13]. The entire article was produced by itself through deep learning, without human processing. The entire article has a central argument and sub-arguments, with detailed examples to support each sub-argument and even human-like emotional expressions in the article. The whole article is no different or even better than the article written by ordinary people from logic to emotion. To make matters worse, in a Georgetown University study on GPT-3, it was found that GPT-3 can be used to produce disinformation and can amplify certain forms of deception that are difficult to detect. Not only that, but the articles and posts it writes are so influential that readers can be easily persuaded by the words and ideas that GPT-3 produces (Knight) [14]. Previously, there had been some bot-created disinformation on social media, but the content was simply a patchwork of words and reprints of other articles (Maddocks) [15]. Once intelligent writing AI like GPT-3 is exploited by people with no bad intentions, they can create stories that are more realistic and detailed than Pizzagate to malign female candidates. A more compelling plot with more specific details will attract a larger audience to read it and will convince more people of the story's truthfulness even if it is itself false.
To make matters worse, today's AI can not only automatically write text-based disinformation, but they can also create more visual false content such as images and videos. Currently, one in five Internet users gets their news through YouTube, second only to Facebook. A moving picture such as a video would give the content more credibility than a literal description (Anderson) [16]. These false images can either be created as disinformation on the Internet alone or added to the false text as visual evidence to make the text more authentic. One example of this is the use of Deepfake software, an artificial intelligence (AI) application that merges, combines, replaces, and overlays images and video clips to create fake videos that look real (Maras \& Alexandrou) [17]. In layman's terms, Deepfake technology replaces one person's face with another's in a video and can do so with a high degree of consistency in expressions, mannerisms, and movements. This technology is now used to weave the faces of political leaders, actresses, comedians, and entertainers into pornographic videos (Hasan \& Salah) [18]. And according to a 2016 InterParliamentary Union survey of women parliamentarians worldwide, $41.8 \%$ of respondents said they had seen fake pornographic images of them on social media to shame them, and that this shames and threats have become a serious barrier to women wanting to participate in politics (Inter-Parliamentary) [19]. For voters on both sides of the aisle, these disinformation circulating on social media can have an impact. For voters who support female politicians, these disinformation can shake their position in the minds of voters. Not only that, but for those who are themselves opposed, disinformation resonate with their own biases against these attacked women candidates. It promotes public misunderstanding and fosters greater hostility from political opponents (Lanoszka) [20]. The probability of a female candidate winning an election is reduced by this effect. If this technology is unregulated, along with the previously mentioned GPT-3 technology that automatically generates text, people will create more negative disinformation about women politicians. These disinformation become more influential in an environment that is already biased against women candidates. With more and more sophisticated disinformation accompanied by a public preference for scandalous women candidates, the image of women candidates will be greatly threatened, along with the neglect and rejection of their political ideas. Therefore, we have reason to fear that in the future, disinformation will have a stronger impact on women's political status, thus increasing gender inequality in American society. Moreover, the disinformation that tends to target women not only exists in politics. In fact, it has extended to aspects such as misogynistic comments on social media platforms and appropriation of beauty standards that manipulates women into altering their natural appearance. The diffusion of misogyny into society creates internalized biases, in both ones that spread 
disinformation and ones that receive disinformation, and eventually harms women's status.

\subsection{Misogyny}

The dissemination of disinformation online intensifies misogyny through the confirmation of already-existing implicit bias and the lack of digital literacy. Misogyny, which explicitly stands for "the dislike of women", describes a disapproving attitude towards women's behavior and hostility towards women's achievements. Some common forms of misogyny in mass media are the over-sexualization of women in films, the depiction of women to have inferior abilities than men, and the demonization of women who fight for their rights or advocate for political power. As those disfavoring depictions of women become prevalent in mass media, viewers cannot easily distinguish factual information and the ones that intentionally spread misogynistic views. The term "manosphere" stands for a set of forums of posts and blogs that advocate for "Men's Rights" (Gotell \&Dutton) [21]. As a result of the prevalence of "manosphere" and internalized misogyny among women themselves, women are more likely to "self-harm" through "hating their bodies", "having low expectations of relationships", "subjugating their own needs to those of others", and "viewing male approval as a form of validation" (O’Hagan) [22].

\subsubsection{Algorithms of social media caused more people to adopt misogynistic views}

The algorithms of social media platforms that "analyzes and predicts attention" enabled misogynistic information to be distributed to viewers that already hold biased opinions about women. Media, in forms of social media platforms such as Facebook and Instagram, is likely to appear as a neutral sharing platform to its users. Over time, users of these media websites are no longer able to identify biases within information and believe what they see on those platforms are neutral. The hyperreality of "neutrality" of information on social media shapes internalized biases, including biased opinions towards women. The implicit biases held by users of social media helps more extreme ideas to disseminate and circulate. The manosphere attracts subscribers by portraying women as "opportunistic creatures who are constantly looking to manipulate 'high status' men" (Gotell \&Dutton) [21]. Those misogynistic forums utilize social media's property as "echo-chamber" to appear on the feed of those like-minded users. Confirmation bias is a psychology term that describes the "tendency to interpret or favor information that confirms existing beliefs" (Noor). Once a "Men's Right" activist publishes a post that attacks feminism's approach, the post will be recommended to the feed of the potential supporters of anti-feminism. Then, some viewers of those anti-feminist posts will adopt more extreme opinions on women and repost these opinions. The misinterpretation of women among those posts is confirmed by both people with explicit bias, those male-supremist groups, and people with implicit bias, viewers that interpret biased misogynistic information as neutral. The algorithms that exist in the basis of social media platforms gather people's behavior and make correlations based on a large set of personal data. Those algorithms further intensify misogyny through recommending posts from "manosphere" to those who might support them, and therefore those posts circulate and gain more supporters.

\subsubsection{The "Beach Body"}

Misogyny is not only intensified by anti-feminist forums that attack females' ability as rational leaders, but also reinforced by followers of unreal beauty standards who lack the literacy to process information. Many female users of social media, especially young adults, and teenagers, unconsciously spread misogyny by following and spreading beauty standards that are against female's natural body anatomy. The setting of social media such as Instagram allows its users to view a large number of images within a short interval of time, and the "fast clicks" don't leave time for users to develop digital literacy that can be used to interpret and question information. As a consequence of lack of literacy, users believe in what they see on social media as reality, including pictures that reflect beauty standards that are impossible to achieve naturally. One common trope that is widely accepted by young women is the "beach body", which stands for being "slim, tanned, young, Caucasian, female and bikinied" (Small) [23]. The "beach body" is widely praised as being "beautiful" on social media platforms. However, the trope is exclusive toward both race and body type, and it represents a subjective way to define beauty. However, many users, especially those of younger age, try to imitate the image by both changing their shape in real life through dieting or alternating their online image. The diet culture that follows the popularity of "beach body" boosts internalized misogyny because women believe that they have to pay a certain price in order to get attention online. The trope also spreads misogyny by encouraging women to dislike their natural body and to try to make "improvements" to conform society's beauty standard. Chiluwa and Samoilenko conducted a study on how students of age 19-23 perceives the "beach body". The results show that even though a majority of them are able to identify the difference between online images and real appearances, they still choose to edit their pictures to be similar to the ideal "beach body" (Kleim, Ackler, \& Tonner) [24]. Pictures that follow the misogynistic beauty ideal get more clicks and likes, and thus are recommended to a larger audience. Then, more people will follow the trend of posting "beach bodies" in order to have more attention. The opportunity to attract attention allures more and 
more young women to follow toxic beauty standards and develop an implicit misogynistic view on women.

\section{CONCLUSION}

This essay sets out to reveal that in America, women's status in society is being trampled more severely by the development of technology. While technology has made it easier for us to access the information we need through social platforms, it also helps malicious individuals spread disinformation to denigrate and fabricate false news about women. Most viewers who do not know the truth behind are likely to believe in what social platforms recommend them to read, even some false information, and it is enough to insult a woman's self-esteem as disinformation successfully prevails among people. Also, we have discussed that the spread of disinformation through AI and algorithms has negatively affected people's attitude toward women in the US and women have suffered from misogyny and the false news in politics. More than that, we use two case studies and analysis to discuss respectively about how women are being affected by disinformation, including fabricated scandals and pornography in political sphere, and in what situations are women suffering from in their social lives.

\section{REFERENCES}

[1]. Buchanan, T. (2020). Why do people spread false information online? The effects of message and viewer characteristics on self-reported likelihood of sharing social media disinformation. PLOS ONE, 15(10), https://doi.org/10.1371/journal.pone.0239666.

[2]. Herrero-Diz, P., Pérez-Escolar, M., \& Plaza Sánchez, J. F. (2020). Gender disinformation: analysing hoaxes on Maldito Feminismo. Revista ICONO14 Revista Científica De Comunicacióny Tecnologías Emergentes, 18(2), 188-216. https://doi.org/10.7195/ri14.v18i2.1509.

[3]. Setzler, M. (2018, November 16). Measuring Bias against Female Political Leadership. Politics \& Gender, $\quad 15 \quad$ (4), $1995-721$. https://doi.org/10.1017/S1743923X18000430.

[4]. Byerly, C. M. (2014). Media conglomeration and women's interests: A global concern. Feminist Media Studies, 14(2), 322-326. doi:10.1080/14680777.2014.909137.

[5]. Carli, L. L., \& Eagly, A. H. (2001). Gender, hierarchy, and leadership: An introduction. Journal of Social Issues, 57(4), 629-636. doi:10.1111/00224537.00232 .

[6]. Kang, C. (2016). Fake News Onslaught Targets Pizzeria as Nest of Child-Trafficking. The New
York

Time.

https://www.nytimes.com/2016/11/21/technology/f act-check-this-pizzeria-is-not-a-child-traffickingsite.html.

[7]. The Guardian. (2017, June 23). 'Pizzagate' conspiracy theorist gets four years in prison. https://www.theguardian.com/usnews/2017/jun/22/pizzagate-conspiracy-theoristprison-sentence-washington

[8]. Mihailidis, P., \& Viotty, S. (2017). Spreadable spectacle in digital culture: Civic expression, fake news, and the role of media literacies in "post-fact" society. American Behavioral Scientist, 61(4), 441454. doi:10.1177/0002764217701217.

[9]. Stabile, B., Grant, A., Purohit, H., \& Harris, K. (2019). Sex, Lies, and Stereotypes: Gendered Implications of Fake News for Women in Politics. Public Integrity, $21 \quad$ (5), 491-502. https://doi.org/10.1080/10999922.2019.1626695.

[10].Persaud, F. J. (2016). Why 'pussygate' will dump trump. Caribbean Today. https://search-proquestcom.aurarialibrary.idm.oclc.org/newspapers/whypussygate-will-dumptrump/docview/1837920499/se-2?accountid=14506

[11].Asiedu, D. (2007). Details of Czechoslovakia's biggest disinformation operation published on web. Czech Radio. https://english.radio.cz/detailsczechoslovakias-biggest-disinformation-operationpublished-web-8607186.

[12].Talwar, S., Dhir, A., Kaur, P., Zafar, N., \& Alrasheedy, M. (2019). Why do people share fake news? Associations between the dark side of social media use and fake news sharing behavior. Journal of Retailing and Consumer Services, 51, 72-82. https://doi.org/10.1016/j.jretconser.2019.05.026.

[13].The Guardian. (2020). A robot wrote this entire article. Are you scared yet, human? https://www.theguardian.com/commentisfree/2020/ sep/08/robot-wrote-this-article-gpt-3.

[14].Knight, W. (2021, May 24). AI Can Write Disinformation Now---and Dupe Human Readers. Wired. https://www.wired.com/story/ai-writedisinformation-dupe-human-readers/.

[15].Maddocks, A. (2020). 'A Deepfake Porn Plot Intended to Silence Me': exploring continuities between pornographic and 'political' deep fakes. Porn Studies, 7 (4), 415-423. https://doiorg.aurarialibrary.idm.oclc.org/10.1080/23268743. 2020.1757499. 
[16].Anderson, K. E. (2018). Getting acquainted with social networks and apps: combating fake news on social media. Library HiTech News, 35(3), 1-6.

[17].Maras, M. H., \& Alexandrou, A. (2019). Determining authenticity of video evidence in the age of artificial intelligence and in the wake of Deepfake videos. International Journal of Evidence \& Proof, 23(3), 255-262. https://doi.org/10.1177/1365712718807226.

[18].Hasan, H. R., \& Salah, K. (2019). Combating Deepfake Videos Using Blockchain and Smart Contracts. IEEE Access, 7: 41596-41606. https://doi.org/10.1109/ACCESS.2019.2905689.

[19].Inter-Parliamentary Union. (2016). Sexism, harassment and violence against women parliamentarians.

http://archive.ipu.org/pdf/publications/issuesbriefe.pdf.

[20].Lanoszka, A. (2019). Disinformation in international politics. European Journal of International Security, 4(2), 227-248. https://doi.org/10.1017/eis.2019.6.

[21].Gotell, L., \& Dutton, E. (2016). Sexual Violence in the 'Manosphere': Antifeminist Men's Rights Discourses on Rape. International Journal for Crime, Justice and Social Democracy, 5(2), 65-80. https://doi.org/10.5204/ijcjsd.v5i2.310.

[22].O'Hagan, E.M. (2018, August 29). Women's selfharm is being fuelled by misogyny. The Guardian. https://www.theguardian.com/commentisfree/2018/ aug/29/women-self-harm-misogyny-socialpressure-pain.

[23].Small, J. (2007). The emergence of the body in the holiday accounts of women and girls. Tourism and Gender: Embodiment, Sensuality and Experience, 73-91.

https://doi.org/10.1079/9781845932718.0073.

[24].Kleim, A. J., Eckler, P., \& Tonner, A. (2019). “Too Good to Be True." Advances in Media, Entertainment, and the Arts, 65-86. https://doi.org/10.4018/978-1-5225-8535-0.ch005. 